МРНТИ 17.09.91

\author{
Исмаилова А.С., \\ диссертант Института фольклора \\ Национальной Академии наук Азербайджана, \\ Азербайджан, г. Баку, е-mail: dilchilik2001@gmail.com

\section{ТИПОАОГИЯ ЖАНРОВ ААСТАН И БАААААА: «КЕРОГАУ» И «РОБИН ГУА»}

\begin{abstract}
«Робин ГуА", имеющий еще в средние века множество вариантов и версий, по своему жанру является балмадой. Баммада - мирический жанр, несущий в себе признаки поэтических форм мирики. Балмада, наряду с мирическими свойствами, также обладает свойствами повествования. Это говорит о том, что в поэтической структуре этого жанра объединяются кирика и эпос. Бамладе присущи не только черты мирики и эпоса, а также черты драмы. Таким образом, балмада по своей природе связана с народными танцами, то есть, с Араматическим видом фольклора. С точки зрения историко-культурной природы и поэтического настроения бамлада несет в себе эпические, мирические и драмматические виды фольк^орных признаков. Эта черта с точки зрения типологии объединяет балмаду с жанром эпоса.
\end{abstract}

Кмючевые слова: бамлада, эпос, Кероглы, Робин ГуА, фольклор.

Ismayilova A.S.,

research assistant of the Institute of Folklore National Academy of Sciences of Azerbaijan, Azerbaijan, Baku, e-mail: dilchilik2001@gmail.com

Typology of epos and ballad genres: «Koroghlu» and « Robin Hood»

The epos of Robin Hood which had a number of variants and versions in the Middle Ages is a ballad according to its genre. A ballad is a lyrical genre first of all, as this genre contains the features of poetical norm of the lyrical type. Besides possessing lyrical features, it has narrative and characteristics as well. The genre of ballad has both lyrical and epic features and it proves that lyrical and epic types have joined in the structure in this genre. A ballad possesses not only the features of lyrical and epic types, but also the features of dramatic types. So, according to its origin a ballad is connected with folk dances, i.e. the drama type of folklore. From the point of view of it is poetic structure the historical and cultural origin of a ballad conveys the peculiarities epical lyric and dramatic types of folklore. This characteric feature combines a ballad with the genre of epos from typological standpoint.

Key words: ballad, epos, Koroghlu, Robin Hood, folklore.

\title{
Исмаилова А.С.,
}

Азербайжан Ұлттық, ғылым академиясы Фольклор институтының диссертанты, Азербайжан, Баку к., e-mail: dilchilik2001@gmail.com

\section{Аастан және бамлада жанрының типологиясы: «Көрұғлұ" және «Робин ГуА"}

«Робин ГуА» - орта ғасырларда көптеген нұсқалар мен баламалары бар, жанры бойынша Балмада болып табылатын шығарма түрі. Балмала - мириканың поэтикалық формаларының белгілерін көрсететін лирикалық жанр. Балмада мирикалық қасиеттермен қатар, баяндау қасиеттеріне ие. Бұл жанрдың поэтикалық құрылымында мирика мен эпос бірігетінін білдіреді. Балладаға ^ирика мен эпостың ғана емес, сондай-ақ, драмалық белгілер де тән. Осылайша, балмада өзінің табиғаты бойынша халық, билерімен, яғни фольклордың драмалық түрімен байланысты. Тарихи-мәдени 
табиғат және балмаданың поэтикалық жай-күйі тұрғысынан фольклорлық, белгілердің эпикалық, мирикалық және драмалық түрлері бар. Типология тұрғысынан бұл көзқарас эпос жанры мен баммаданы біріктіреді.

Түйін сөздер: бамлада, эпос, Көрұғлұ, Робин Гуд, фольклор.

\section{Введение}

«Кероглу» является творческим фольклорным памятником тюркских народов. Известно, что возникшие в устной форме и в этой же форме существующие, передаваемые из поколения в поколение произведения творчества считаются фольклором. И эпосы «Кероглу» и «Робин Гуд», хотя и появились в разных историко-географических пространствах, с точки зрения типологии возникновения являются фольклорными памятниками. Как «Кероглу» возник из сочиненных легенд, преданий, песен о героях, заработавших уважение народа своей борьбой, так и «Робин Гуд» сформировался этим же способом. В этом контексте оба памятника являются фольклорным памятником, продуктом народного творчества. «Кероглу» как продукт азербайджанского устного народного творчества в жанре дастана, а «Робин Гуд»-в жанре баллады. Хотя «дастан» и «баллада» являются разными словами, они указывают на типологически близкие, схожие жанры. То есть и дастан, и баллада типологически представляют собой героический эпос.

\section{Эксперимент}

Главная цель в написании статьи заключается в изучении типологии жанра дастан и баллада на основе памятников «Кероглы» и «Робин Гуд».

Еще со средних веков имеющий множество вариантов и версий эпос «Робин Гуд» по своему жанру является балладой. Сравнение образов Кероглу и Робина Гуда требует сначала пристального внимания к значению термина «баллада», его сравнения с термином «дастан».

Е. Аксенова пишет, что «баллада» происходит от провансальского слова «ballar» и означает танцевать. Баллада - жанр лирической поэзии, имеющий характер повествования. Жанр баллады возник, развившись из широко распространенных в средние века народных танцев любовного содержания (Aksenova, 1974: 24).

Баллада, с точки зрения историко-культурного происхождения, поэтического строя носит в себе признаки эпического, лирического и драматического видов. Эта черта объединяет типологически балладу с жанром дастан.
Что касается жанра дастан, наблюдаемые в жанре баллады свойства можно увидеть и в нем. Начиная с «Книги моего Деда Коркута», героические эпосы как «Кероглы», в том числе все любовные дастаны, с точки зрения поэтического строя состоят из поэтической и называемой «юрд» прозаической частей.. То есть в дастане перемешались свойства лирических и эпических видов. Однако представить дастаны вне пределов драматических элементов тоже нельзя. Так, дастан насыщен диалогами. Ашуг исполняет дастан как актёр, озвучивает диалоги в нем. С другой стороны, и возникновение баллад развитием из широко распространенных в средние века народных танцев любовного содержания составляет типологическую идентичность с дастаном «Кероглу». И в возникновении дастана «Кероглу» есть большая роль сочиненных в честь народных героев песен, воспевающих их борьбу.

Жанр баллада. Хотя жанр баллады, и соединяет в себе, можно сказать, все элементы английского народного творчества, название жанра связано непосредственно с танцами и музыкой. Как отмечалось в данных о жанре сведениях, баллады о «Робин Гуде» сохранились в форме стихотворений с сюжетом. Слово «баллада» образовалось из общего корня со словом «балет». В самом начале сопровождаемые танцами народные песни назывались балладами (Robin Gud / http://mycelebrities.ru/publ/ ).

И другие данные об этом жанре показывают что, «баллада» объединяет в себе основные элементы всех видов народного творчества. Любопытно, что как «дастан» распространившись среди народов Востока, обрел широкое терминологическое значение, так и жанр баллады, распространившись среди европейских народов, прошел обширный путь развития. Рассмотрим краткое объяснение, данное термину:

1. Баллада (от французского слова «ballade», латинского «ballo» - «танцую») - лирический жанр французской литературы в XIV-XV веках, обладающий устоявшейся формой. В английской народной поэзии лироэпический жанр и одинаковый с ним поэтический жанр в романтизме. Романтические баллады представляют собой стихотворения с сюжетами, построенными на основе фантастических, фольклорных, 
легендарно-исторических, бытовых материалов (Ballada // http://slovar.lib.ru).

2. Во Франции баллады писал знаменитый баснописец Лафонтен в XVII веке. В содержании немецких баллад превалирует печальный характер. В русской литературе баллада появилась в начале XIX века (Ballada // https://ru.wikipedia. org ).

Таким образом, «баллада» и «дастан» объединяют в себе эпические, лирические, драматические, музыкальные, танцевальные элементы. В этом плане, то, что «Кероглу» жанрово является дастаном, а «Робин Гуд» балладой, не создает между ними основательных различий. Оба они являются народным эпосом, и их эпичность является самой важной типологической почвой, объединяющей эти два эпоса.

Дастан «Кероглу» по структурной форме опирается на чередование поэзии с прозой. А «Робин Гуд» от начала и до конца в стихах. Данная черта выглядит одной их коренных отличий между дастаном и балладой. Однако при взгляде на данный вопрос в контексте истории азербайджанского эпоса это различие само-собой устраняется.

Как известно, традиция азербайджанского героического эпоса начинается с «Книги моего Деда Коркута». Темой этого эпоса является героизм. От начала и до конца он посвящен геройствам огузских храбрецов (Kniga, 1988: 5). Текст дастана возник из единства героического духа, поэзии и музыки.

Поэтическае форма и поэтический дух в целом в дастане «Деде Коркут» привлекают внимание во всем тексте. Покойный ученый-коркутовед Т. Гаджиев выдвинул следующую мысль о том, что в эпосе «Книга Деде Коркута» на самом деле «прозы» нет, дастан от начала и до конца состоит из поэзии: поэтическая технология «Книги отца Коркута» не изучена на нужном уровне. Составлявшие и издававшие «Книгу» в разные периоды ученые указывали на разное количество образцов поэзии в тексте. Каждый из этих ученых, через раз видевших стихотворения в дастане, от начала до конца являющемся стихотворением, естественно, сильно ошибались» (Gadjiev, 2004: 14). В «Книге Деде Коркута» прозы нет вовсе, от начала и до конца текст состоит из стихотворения, и здесь стихотворения не могут чередоваться ни с чем, или вернее, с чем-то отсутствующим. Просто в «Книге» есть две формы выражения поэзии: эпико-изобразительная поэзия, интенсивная поэзия. Подача явлений, событий происходит с помощью эпи- ко-изобразительной поэзии. В моменты психологического напряжения, активного лиризма ритм упорядочивается, становится более продолжительным» (Gadjiev, 2004: 29). Т. Гаджиев так подытоживает свои взгляды: «Все еще есть те, кто создает полемику о стихотворности или прозаичности содержания «Книги Деде Коркута». Согласно нашим личным предположениям, «Книга» написана в поэтической форме. К подобному выводу мы пришли после неоднократных сравнений с тюркской фольклорной поэзией и образцами средневековой тюркской поэзии» (Gadjiev, 2004: 3).

В дастане «Кероглу» поэзия чередуется с прозой. Это чередование, в действительности, является основным показателем героических эпосов, в том числе и эпоса «Кероглу». Поскольку героизм, в первую очередь, связан с эпическим видом, то есть с изображением событий. В дастане «Кероглу» традиция эпико-изобразительной поэзии, идущая из «Книги Деде Коркута», превратилась в прозаическое повествование, интенсивная поэзия же свое развитие продолжила как поэзия.

«Робин Гуд» как баллада является именно героическим эпосом. Главный герой произведения Робин Гуд является знаменитым героем средневековых английских народных баллад. Согласно обобщенным данным о Робине Гуде, он был вождем лесных разбойников. Согласно преданиям, со своей ватагой разбойничал, грабил богатых, раздавал бедным награбленное в Шервудском лесу в окрестностях Ноттингема.

В георгафии дастана «Кероглы» основное ядро указывает на древнюю огузскую эпическую традицию. А в этой традиции азербайджанский вариант «Кероглу» играет роль ядра. Идентичную ситуацию можно наблюдать и в традиции, связанной с эпосом «Робин Гуд». Баллада-эпос возникла в Англии, развилась, превратилась в стабильную эпическую традицию, а затем распространилась.

Как известно, баллады о «Робин Гуде» не появились внезапно. Согласно исследователям, эпос «Робин Гуд», корнями, происхождением связанный с народным движением, появился на основе преданий, легенд, песен об исторической личности.

Изучение образа Кероглы в качестве героя дастана показывает, что данный образ тесно связан с первым предком огузов, образом мифического Огуз-кагана. Это естественное явление. Каждый герой эпоса должен быть связан с мифическими корнями на почве эпической тра- 
диции. Поскольку дастан свои истоки берет из мифа, легенд о первом мифическом герое. Огузкаган является первым предком огузов. На основе легенд, преданий, рассказов о нем был создан дастан «Огуз-каган». И эпос «Кероглы» также является продолжением традиции «Огузнаме».

\section{Заключение}

Таким образом, образ Робин Гуда, как и Кероглы, связан с мифическими взглядами. Как Кероглы привязан к образу мифического предка Огуз-кагана, так и Робин Гуд связан с образом, известным в германской мифологии под именами Вотана, Водена, Одина. Головной убор образа этого идолопоклоннического верховного бога, кроме того, скрывает его лицо как некая вуаль-маска. И наличие головного убора, шапки у образа Робин Гуда акцентируется особо. Можно полагать, что здесь указанная шапка является основной чертой в образе Робин Гуда, сохраненной от образа Вотана-Водена-Одина из германской мифологии.
Связь образов Робин Гуда и Кероглы с мифическими воззрениями представляет собой типологическую сторону, свойственную героическим эпосам. Эпический герой обладает отличающейся от всех прочих героев силой, качествами, средствами. В эпосе источником этих необычных сил и средств является мифология. Как азербайджанский дастан «Кероглы» свое начало берет из мифологии, так и английская баллада «Робин Гуд» связана с мифологическими источниками. Мифология представляет собой начало национальной культуры каждого народа. В фольклоре не может быть такого образа, которой какой-либо чертой не был бы связан с мифическими значениями. В фольклоре даже реальные исторические события обретают мифические, легендарные, магические черты. Причина этого заключается в том, что зародыш фольклора составляет мифлогия. Как можно видеть, привязанность к мифическим корням, мифическим взглядам проявляется в качестве одного из типологических признаков, объединяющих жанры дастана и баллады.

\section{Литература}

Аксенова Е. Очерк «Баллада» / Словарь литературоведческих терминов. - М.: Просвещение, 1974. - С. $24-25$.

Робин Гуд - Средневековые легенды и предания - http://mycelebrities.ru/publ/mify_i_legendy/skazanija_srednevekovoj_ evropy/robin_gud/115-1-0-785

Баллада - Словарь литературоведческих терминов - http://slovar.lib.ru/dictionary/ballada.htm

Баллада - Википедия - https://ru.wikipedia.org/wiki/Баллада

Книга моего Деда Коркута / Предисловие, составление и транскрипция Ф. Зейналов и С. Ализаде. - Баку: Писатель, 1988. - 265 c.

Гаджиев Т. Деде Коркут наше прошлое // Журнал «Деде Коркут». - 2004. - № 2. - С. 12-16.

Гаджиев Т. Поэтическое мастерство Орхонских дастанов / Исследования по Азербайджанскому устному народному творчеству. книга XV. - Баку: Сада, 2004. - С. 3-54.

Гаджиев Т. Еще раз о поэтике «Книги Деде Коркута» // Журнал «Деде Коркут». - 2005. - № 1. - С. 3-16.

Робин Гуд - Википедия - https://ru.wikipedia.org/wiki/Робин_Гуд

Фрезер Дж. Дж. Золотая ветвь. - М.: Издательство политической литературы, 1980. - 828 с.

Жирмунский В.М. Тюркский героический эпос. - Ленинград: Наука, 1974. - 727 с.

Джафероглы А. Антропонимический строй песен Деде Коркута // Сборник исследований тюркского языка. - Анкара, 1959. - С. 59-80.

Рзасой С. Парадигмы огузского мифа. - Баку: Сада, 2004. - 200 с.

История о Робин Гуде - http://www.pravda.ru /science /mysterious /past /21-09-2012/1126629-robin_hood_1-0/

\section{References}

Aksenova E. (1974). Ocherk «Ballada» [Sketch «Ballad»] Dictionary of literary terms. Moscow: Prosvesheniye. P. 24-25. (in Russian)

Ballada [Ballad] Dictionary of literary terms//http://slovar.lib.ru /dictionary /ballada.htm (in Russian)

Ballada [Ballad] Wikipediya // https://ru.wikipedia.org/wiki/Баллада (in Russian)

Frezer J. (1980). Zolotaya vetv [Gold branch]. Moscow: Publishing house of political literature, 828 p. (in Russian) baijani)

Gadjiev T. (2004). Dede Korkut nashe proshloye [Dede Korkut is our past] Journal «Dede Korkut». № 2. P. 12-16. (in Azer-

Gadjiev T. (2004) Poeticheskoe masterstvo orhonskih dastanov [Poetic features of the Orkhon eposes] Researches on the Azerbaijani folklore. book XV. Baku: Sada. P. 3-54. (in Azerbaijani) 
Gadjiev T. (2005) Eshe raz o poetike «Knigi Dede Korkuta» [Again about poetics of the «Book of Dede Korkut»] Journal «Dede Korkut», № 1. P. 3-16. (in Azerbaijani)

Istoriya o Robin Gude [History about Robin Hood] - http:// www. pravda. ru/science/mysterious /past/21-09-2012/1126629-robin_hood_1-0/ (in Russian)

Jaferoglu A. (1959). Antroponimicheskiy stroy pesen Dede Korkuta [Antroponymic system of songs Dede Korkut] Collection of researches of Turkic language. Ankara. P. 59-80. (in Turkish)

Jirmunski V.M. (1974). Tyurkskiy geroicheskiy epos [Turkic heroic epos]. Leningrad: Nauka. 727 p. (in Russian)

Kniga moeqo Deda Korkuta (1988) [The book of Dede Korkut]. Baku: Pisatel. 265 p. (in Azerbaijani)

Robin Gud [Robin Hood] Wikipediya // https://ru.wikipedia.org /wiki/ Робин_Гуд (in Russian)

Robin Gud - Srednevekoviye legendi i predaniya [Robin Hood - Medieval legends] http://mycelebrities.ru/publ/mify_i_legendy/skazanija_srednevekovoj_evropy/robin_gud/115-1-0-785 (in Russian)

Rzasoy S. (2004). Paradigmi oguzskogo mifa [Paradigms of the oguz myth] Baku: Sada, 2004. 200 p. (in Azerbaijani) 
МРНТИ 17.07.41

\author{
Муминов С.O., \\ к.п.н., доцент Казахского национального университета им. аль-Фараби, \\ Казахстан, г. Алматы, e -mail: s.muminov2012@yandex.kz

\section{РОМАН А. БЕАОГО «ПЕТЕРБУРГ» В КОНТЕКСТЕ ЗАРУБЕЖНОГО МОАЕРНИЗМА}

Роман Андрея Белого «Петербург» находится в контексте развития западной китературы. Поэтика романов Андрея Белого и Ажойса основана на сокращении антропологических характеристик митературных персонажей.

Оба писателя активно используют гротеск, иронию и пародию. Эти источники комического эффекта способствуют сокращению антропологической поэтики, характерной Аля реалистической митературы. Художественные сатирические приемы основаны на концентрации и обобщении человеческих характеристик (гротеск), на игре смыслов (ирония и пародия). Кроме того, значительная часть сатирических приемов искажает, даже схематизирует облик человека.

В романе «УАисс» Ажойс рисует распавшиеся образы персонажей, расширяет художественный мир, вк^ючая пространственные образы и культурный контекст. Это сближает творческий метоА Ажойса с поэтикой Андрея Белого, в романе которого «Петербург» представлены лаконичные портреты персонажей, превратившихся в тени, глобальные образы России, Петербурга, Востока и Запада, играющие заметную роль в произведении.

Очевидно также, что Пруст и Андрей Белый на сходных принципах обновили жанр романа. Последовательный интерес писателей к прошлому, высокий статус онтологических образов в их романах, единый поток прошлого и настоящего, сокращенные антропологические свойства персонажей - вот что сближает романы Пруста и Андрея Белого.

Ключевые слова: Андрей Белый, роман «Петербург», роман, М.Пруст, Ажойс, новаторство.

\title{
Muminov S.O.,
}

$\mathrm{PhD}, \mathrm{A} /$ Professor of al-Farabi Kazakh National University, Kazakhstan, Almaty, e-mail: s.muminov2012@yandex.kz

\section{The novel of A. Bely «Petersburg» in the context of foreign modernism}

Andrei Bely's novel "Petersburg» is in the context of the development of Western literature. The poetics of Andrei Bely and Joyce's novels is based on the reduction of anthropological characteristics of literary characters.

Both writers actively use grotesque, irony and parody. These sources of comic effect contribute to the reduction of anthropological poetics characteristic of realistic literature. Satirical art techniques based on the concentration and synthesis of human characteristics (the grotesque), on the game of meaning (irony and parody). In addition, a significant part of satirical techniques distorts, even schematizes the appearance of a person.

In the novel «Ulysses» Joyce draws broken images of characters, expands the artistic world, including spatial images and cultural context. This brings together the creative method of Joyce with the poetics of Andrei Bely, whose novel «Petersburg» presents laconic portraits of characters that have turned into shadows, global images of Russia, Petersburg, East and West, playing a significant role in the work.

It is also obvious that Proust and Andrei Bely updated the genre of the novel on similar principles. The writers' consistent interest in the past, the high status of ontological images in their novels, the single stream of the past and the present, the reduced anthropological properties of the characters - that's what brings together the novels of Proust and Andrei Bely.

Key words: Andrei Bely, the novel «Petersburg», novel, M. Proust, Joyce, innovation. 